\title{
Tracking of pedometer-determined physical activity in adults who relocate: results from RESIDE
}

\author{
Catrine Tudor-Locke*1, Billie Giles-Corti ${ }^{2}$, Matthew Knuiman ${ }^{2}$ and \\ Gavin McCormack ${ }^{3}$
}

\begin{abstract}
Address: ${ }^{1}$ Walking Behavior Laboratory, Pennington Biomedical Research Center, Baton Rouge, LA, USA, ${ }^{2}$ Centre for the Built Environment and Health, School of Population Health, The University of Western Australia, Crawley, WA, Australia and ${ }^{3}$ Currently Population Health Intervention Research Centre, University of Calgary, Alberta, Canada, Formerly Centre for the Built Environment and Health, School of Population Health, The University of Western Australia, Crawley, WA, Australia
\end{abstract}

Email: Catrine Tudor-Locke* - Tudor-Locke@pbrc.edu; Billie Giles-Corti - Billie.Giles-Corti@uwa.edu.au; Matthew Knuiman - matthew.knuiman@uwa.edu.au; Gavin McCormack - gmccorma@ucalgary.ca

* Corresponding author

\section{Published: 7 August 2008}

International Journal of Behavioral Nutrition and Physical Activity 2008, 5:39 doi:10.1 186/1479-5868-5-39
Received: 14 December 2007

Accepted: 7 August 2008

This article is available from: http://www.ijbnpa.org/content/5/I/39

(C) 2008 Tudor-Locke et al; licensee BioMed Central Ltd.

This is an Open Access article distributed under the terms of the Creative Commons Attribution License (http://creativecommons.org/licenses/by/2.0), which permits unrestricted use, distribution, and reproduction in any medium, provided the original work is properly cited.

\begin{abstract}
Background: This secondary analysis investigated the extent and pattern of one-year tracking of pedometerdetermined physical activity in people who relocated within the same metropolitan area (TI: baseline and T2: post-relocation). Specifically, data were derived from the RESIDential Environment Project (RESIDE), a natural experiment of people moving into new housing developments.

Methods: I, 175 participants ( $49 \mathrm{I}$ males, age $=42.6 \pm 12.7$ years, BMI $=27.2 \pm 9.9 \mathrm{~kg} / \mathrm{m}^{2} ; 684$ females, age $=4 \mathrm{I} .2$ $\pm I I .3$ years, BMI $=25.4 \pm 5.2 \mathrm{~kg} / \mathrm{m}^{2}$ ) wore a Yamax pedometer (SW-200-024) for seven days during the same season at both time points. Pearson's product-moment and Spearman's rank order correlations were used to evaluate the extent of tracking of mean steps/day. Age categories were set as youngest-29.9 ( 19 was the youngest in males, 20 in females), 30-39.9, 40-49.9, 50-59.9, and 60-oldest (78 was the oldest in males, 71 in females). Change in steps/day was also described categorically as: I) stably inactive $<7,500$ steps/day; 2 ) decreased activity (moved from $\geq 7,500$ to $<7,500$ steps/day between TI and T2); 3) increased activity (moved from $<7,500$ to $\geq$ 7,500 steps/day between $\mathrm{TI}$ and T2); and, 4) stably active $\geq 7,500$ steps/day at both time points. Stratified analyses were used to illuminate patterns by sex, age, and BMI-defined weight categories.

Results: Overall, there was a small (non-significant) decrease in steps/day between TI and T2 (mean \pm SD is -8 I $\pm 3,090$ with $95 \% \mathrm{Cl}-259$ to 97 ). With few exceptions (i.e., older women), both Pearson's and Spearman's correlations were moderate $(r=0.30-0.59)$ to moderately high $(r=0.60-0.70)$. The relative change/stability in steps/day (cut at 7,500 steps/day) was not significant across age groups in males $\left(\chi^{2}=17.35, p=.137\right.$ ) but was in females $\left(\chi^{2}=50.00, p<.000 \mathrm{I}\right)$. In both males and females the differences across BMI categories was significant $\left(\chi^{2}=22.28, p=.001\right.$ and $\chi^{2}=15.70, p=.015$, respectively). For both sexes, those in the obese category were more stably inactive (and less stably active) between assessment points compared with those who were categorized as normal weight.
\end{abstract}

Conclusion: Despite relocation, Western Australian adults held their rank position to a moderate to moderately high extent over one year. Categorized and expressed as relative stability/change over time, sex, age, and BMI patterns were evident. 


\section{Introduction}

Tracking, with regards to physical activity behaviors, refers to the extent to which an individual maintains relative position or rank over time [1]. Patterns of tracking include those categorized by sex, age, and indicators of body mass index (BMI)-defined weight status and physical activity levels that meet suggested cut points for health-related benefits. To date, much of the tracking literature has focused on young populations as they transition through adolescence $[2,3]$ and beyond to adulthood $[4,5]$. Tracking with objective monitoring instruments has only been conducted in small samples of very young children (using accelerometers) $[6,7]$ and adolescents (using pedometers) [2]. Limited information is available about tracking within adult populations [8] or across simple life span events such as relocation of primary residence. More than 39 million Americans (or about $14 \%$ of the population) changed addresses in 2004-2005 [9]. In Australia, over 3 million people (or almost $18 \%$ of the population) moved residences in 2000-2001 [10].

To our knowledge, no previous attempt has been made to describe tracking of adult physical activity behavior (objectively monitored or otherwise) disrupted by relocation. Therefore, the purpose of this secondary analysis was to investigate the extent and pattern of tracking of pedometer-determined physical activity between measures taken one year a part in a sample that moved residences within Perth, Western Australia, in the interim.

\section{Methods}

The RESIDential Environments Project (RESIDE) is a natural experiment to evaluate the impact of urban design policies intended to encourage more active transport behaviors through the creation of safe, convenient pedestrian-friendly neighborhoods with access to shops, transit and parkland. As part of its longitudinal design, people moving into housing developments in Perth, Western Australia, were invited to participate in recurrent surveys and physical activity assessment using pedometers. Details about the selection of housing developments and subsequent recruitment of participants are provided in another publication [11]. All participants received written information about the study and provided written consent before providing any personal data. The present manuscript focuses on participants' baseline (T1) and 12month follow-up (T2; after having moved to their new home) data points and presents a novel analysis not previously published. Specifically, participants were sent a T1 questionnaire and pedometer up to three months before the anticipated completion of their new home. The T2 questionnaire was sent approximately 12 months later with the aim that questionnaires and pedometer monitoring be completed in the same season.
Participants were asked to wear a Yamax-Digiwalker pedometer (SW-200-024) for seven days. This model has been shown to provide valid and reliable data $[12,13]$. Participants were asked to attach the pedometer to the waist-band of their clothing or belt at the front of the hip. Day-end steps were recorded in a log each night before retiring to bed. Participants were instructed to not reset the pedometer, except at the start of the first day of wearing the device. Thus a cumulative step-count was captured. In addition, participants recorded whether the pedometer was worn each day (i.e., all day, some of the day or not at all) or if the device had been removed for any reason throughout the day (e.g., for bathing, showering, or swimming).

Pedometer-determined steps for each day (except for day 1) were derived from the cumulative count by subtracting the previous day's steps from the current day's steps. Data were then screened for extreme values. Data for any single day indicating $<1,000$ steps were removed and values $>$ 30,000 steps on any single day were truncated (i.e., replaced with 30,000 steps). Equivalent cut points have been used to identify outliers among younger individuals [14]. Moreover, these cut points appear reasonable for our data given that the minimum and maximum daily steps found in a previous population-based study of Western Australian adults was 982 and 20,221 steps, respectively [15]. Mean steps/day for T1 and T2 were computed from the total weekly steps divided by the total days $(6.5 \pm 1.3$ days overall) the pedometer was worn.

Other variables extracted from the original data set included sex, age and BMI (based on self-reported height and weight) at T1. Overall, 1,813 participants completed questionnaires at $\mathrm{T} 1$, and $75 \%$ of these participants $(\mathrm{n}=$ 1,356 ) returned completed T2 questionnaires. Data were reduced to include only those cases with complete pedometer data at both time points, BMI at $\mathrm{T} 1$, and those women who were not pregnant at $\mathrm{T} 2$ and reported no children less than 2 years of age at T2 (these latter two to conservatively exclude women considered pregnant at either time point). In total, 51 cases were missing some pedometer data, 48 were missing BMI data, 25 women were pregnant at $\mathrm{T} 2$ and 57 women had children less than 2 years at T2. After reductions, the final analysis data set used herein comprised of 1,175 cases $(491$ males, age $=$ $42.6 \pm 12.7$ years, $\mathrm{BMI}=27.2 \pm 9.9 \mathrm{~kg} / \mathrm{m}^{2} ; 684$ females, age $=41.2 \pm 11.3$ years, $\mathrm{BMI}=25.4 \pm 5.2 \mathrm{~kg} / \mathrm{m}^{2}$ ). There were no significant differences in steps/day or BMI from the original full data set; however, those in the reduced data set were on average 6.9 years older $(\mathrm{p}<0.000)$. Age categories were set as youngest-29.9 (19 was the youngest in males, 20 in females), 30-39.9, 40-49.9, 50-59.9, and 60 -oldest (78 was the oldest in males, 71 in females). 
Descriptive analysis included computation of mean \pm SD pedometer-determined physical activity (steps/day) at $\mathrm{T} 1$, $\mathrm{T} 2$, and mean \pm SD change $(\Delta)$ between T2 and T1. A negative $\Delta$ indicates a decrease over time; a positive $\Delta$ indicates an increase. Pearson's product-moment and Spearman's rank order correlations were used to evaluate extent of tracking of steps/day. Malina's [1] suggestions for interpreting correlations were used: $<0.30$ is low, $0.30-0.59$ is moderate, and $\leq 0.60$ is moderately high. Patterns of tracking were explored across sex-and age-specific categories, and initial BMI-defined weight categories (normal weight $=\mathrm{BMI}<25 \mathrm{~kg} / \mathrm{m}^{2}$, overweight $=\mathrm{BMI} \geq 25$ $\mathrm{kg} / \mathrm{m}^{2}$ to $<30 \mathrm{~kg} / \mathrm{m}^{2}$, and obese $\left.=\mathrm{BMI}>30 \mathrm{~kg} / \mathrm{m}^{2}\right)$ using ANOVA (first by sex and age category, and secondly by sex and BMI-defined weight category) and stratified analyses.

Change in steps/day was also described categorically as: 1) stably inactive $<7,500$ steps/day; 2) decreased activity (moved from $\geq 7,500$ to $<7,500$ steps/day between T1 and T2); 3 ) increased activity (moved from $<7,500$ to $\geq$ 7,500 steps/day between T1 and T2); and, 4) stably active $\geq 7,500$ steps/day at both time points. The dichotomous cut point 7,500 steps/day was selected since evidence indicates that health benefits can be realized and that accepted public health recommendations are achievable at this threshold [16-18]. Stratified analyses were used to illuminate patterns by sex, age, and BMI-defined weight categories. Chi-square analyses were interpreted for significance. SPSS 15 was used and alpha was set at $\mathrm{p}<0.05$.

\section{Results}

Table 1 presents pedometer-determined physical activity (steps/day) at T1, T2, and change between $\mathrm{T} 2$ and $\mathrm{T} 1$. ANOVA (with between-subjects factors of sex and age category) indicated an overall small but not quite significant change in steps/day (i.e., lower mean steps/day at T2; F = $3.724, \mathrm{df}=1, \mathrm{p}=.054$ ) and no significant effects (or interaction effects) of sex or age category. Overall, mean \pm SD for $\Delta$ was $-81 \pm 3,090$ steps/day with $95 \%$ CI $(-259,97)$.

Table 1 also displays Pearson and Spearman correlations computed between $\mathrm{T} 1$ and $\mathrm{T} 2$ steps/day, collated by sex and age category. Overall, both Pearson and Spearman correlations were moderate to moderately high. This suggests that individuals within the groups held their rank position to a moderate extent between assessments. A singular exception was observed in females $60+$ years of age; the Pearson correlation $(0.238$; low) was non-significant, however, the Spearman correlation $(0.304$; moderate) was statistically significant.

Table 2 presents sex-and BMI-defined weight category strata of pedometer-determined physical activity (steps/ day) at T1, T2, change $(\Delta)$ between T2 and T1, and Pearson and Spearman correlations. ANOVA (with between- subjects factors of sex and BMI-defined category) revealed a significant effect of BMI-category on $\Delta$ steps/day (F = $3.100, \mathrm{df}=2, \mathrm{p}=.045$ ); no other effects (or interactions) were significant. Again, both Pearson and Spearman correlations were moderate to moderately high. This suggests that individuals within lower BMI-defined weight categories (i.e., normal weight) were relatively more stable in their rank position over time than those in higher BMIdefined weight categories (i.e., obese).

The relative change/stability in steps/day (cut at 7,500 steps/day) by sex and age category is presented in Figure 1. In males, the difference in relative change/stability in steps/day across age categories was not significant $\left(\chi^{2}=\right.$ $17.35, \mathrm{p}=.137)$, however, in females the difference was significant at $\left(\chi^{2}=50.00, \mathrm{p}<.0001\right)$. Specifically, the proportion of females categorized as stably active was lower in the youngest age group, was higher in the second and third age groups, and lower again in the older age groups. Differences in the proportion of females who are stably inactive are a mirror image of this observation.

The relative change/stability in steps/day (cut at 7,500 steps/day) by sex and BMI-defined weight category is presented in Figure 2. In both males and females the differences across BMI categories was significant $\left(\chi^{2}=22.28\right.$, $\mathrm{p}$ $=.001$ and $\chi^{2}=15.70, \mathrm{p}=.015$, respectively). Notably, for both sexes, those in the obese category were more stably inactive (and less stably active) between assessment points than those who were categorized as normal weight.

\section{Discussion}

These data represent the first known longitudinal pedometer data in adults. Previously, Raustorp and colleagues [2] reported pedometer tracking data for 97 Swedish adolescents assessed three times over five years, essentially capturing their development between 12 and 17 years of age. Pearson's correlations indicated low to moderate tracking in these adolescents, with patterns of higher tracking in boys than girls (i.e., correlations ranged from 0.55 in boys to 0.22 in girls). Most of the earlier tracking studies (children, adolescents, and adult) have relied on self-reported behaviors [1]. Spearman correlations for adult men and women were 0.31 and 0.23 , respectively, in a large British cohort assessed on self-reported frequency of leisure physical activity at 33 and 42 years of age [8]. Spearman correlations ranged from -0.10 to 0.33 for self-reported time in physical activity assessed 7 years apart in a Canadian adult population [19]. In the present study, we found that pedometer-determined physical activity behavior tracks to a relatively higher extent over one year in Australian adults disrupted by relocation, than both pedometer-assessed physical activity in adolescents and self-reports of physical activity in adults. Specifically, most of the correlations evaluated herein (both Pearson's and Spearman's) fit 
Table I: Sex-and age-category strata of mean \pm SD steps/day

\begin{tabular}{|c|c|c|c|c|c|}
\hline & $\begin{array}{c}\text { TI } \\
\text { Steps/day }\end{array}$ & $\begin{array}{c}\text { T2 } \\
\text { Steps/day }\end{array}$ & $\begin{array}{c}\text { Pearson's } \\
r\end{array}$ & $\begin{array}{c}\text { Spearman's } \\
r\end{array}$ & $\begin{array}{c}\Delta=\text { T2 - TI } \\
\text { Steps/day } \\
(95 \% \mathrm{Cl})\end{array}$ \\
\hline \multicolumn{6}{|c|}{ Youngest-29.9 years } \\
\hline Males $(n=77)$ & $9,610 \pm 4,558$ & $9,471 \pm 4,247$ & $.650 *$ & $.65 I^{*}$ & $\begin{array}{c}-139 \pm 3,695 \\
(-977,700)\end{array}$ \\
\hline Females $(n=103)$ & $8,076 \pm 3,324$ & $7,981 \pm 3,322$ & $.567 *$ & $.566^{*}$ & $\begin{array}{l}-94 \pm 3,091 \\
(-698,510)\end{array}$ \\
\hline \multicolumn{6}{|c|}{$30-39.9$ years } \\
\hline Males $(n=148)$ & $8,973 \pm 3,430$ & $8,932 \pm 3,209$ & $.627^{*}$ & $.54 I^{*}$ & $\begin{array}{l}-41 \pm 2,876 \\
(-509,427)\end{array}$ \\
\hline Females $(n=245)$ & $8,859 \pm 3,177$ & $9,174 \pm 3,091$ & $.555^{*}$ & $.523 *$ & $\begin{array}{c}315 \pm 2,957 \\
(-57,687)\end{array}$ \\
\hline \multicolumn{6}{|c|}{$40-49.9$ years } \\
\hline Males $(n=118)$ & $9,067 \pm 3,720$ & $8,660 \pm 3,186$ & $.610^{*}$ & $.560^{*}$ & $\begin{array}{c}-407 \pm 3,088 \\
(-970,156)\end{array}$ \\
\hline Females $(n=165)$ & $9,017 \pm 2,936$ & $9,170 \pm 3,080$ & $.530 *$ & $.543 *$ & $\begin{array}{c}153 \pm 2,920 \\
(-296,602)\end{array}$ \\
\hline \multicolumn{6}{|c|}{$50-59.9$ years } \\
\hline Males $(n=89)$ & $7,833 \pm 2,908$ & $7,733 \pm 3,410$ & $.529 *$ & $.533^{*}$ & $\begin{array}{c}-100 \pm 3,097 \\
(-752,553)\end{array}$ \\
\hline Females $(\mathrm{n}=\mathrm{III})$ & $8,749 \pm 3,702$ & $8,342 \pm 3,189$ & $.606 *$ & $.645^{*}$ & $\begin{array}{c}-407 \pm 3,091 \\
(-988,174)\end{array}$ \\
\hline \multicolumn{6}{|c|}{ 60-oldest } \\
\hline Males $(n=59)$ & $7,982 \pm 3,261$ & $7,206 \pm 3,298$ & $.596 *$ & $.542 *$ & $\begin{array}{c}-776 \pm 2,946 \\
(-1,544,-8)\end{array}$ \\
\hline Females $(n=60)$ & $7,139 \pm 2,780$ & $6,732 \pm 3,260$ & .238 & $.304^{*}$ & $\begin{array}{l}-408 \pm 3,747 \\
(-1,376,561)\end{array}$ \\
\hline \multicolumn{6}{|c|}{ Total sample } \\
\hline Males $(n=491)$ & $8,769 \pm 3,635$ & $8,527 \pm 3,494$ & $.621 *$ & $.572 *$ & $\begin{array}{c}-243 \pm 3,112 \\
(-519,33)\end{array}$ \\
\hline Females $(n=684)$ & $8,610 \pm 3,240$ & $8,644 \pm 3,235$ & $.550 *$ & $.55 I^{*}$ & $\begin{array}{l}34 \pm 3,07 \mid \\
(-197,264)\end{array}$ \\
\hline
\end{tabular}

Note: 19 was the youngest in males, 20 in females; 78 was the oldest in males, $7 \mathrm{l}$ in females. ${ }^{*}$ correlation is significant at the $0.0 \mathrm{I}$ level (2-tailed)

within Malina's [1] suggested ranges for moderate to moderately high tracking of physical activity behavior. The primary exception was in older females. This group was comparatively less stable in behavior over time, that is, characterized by a less predictable shifting in rank order between time points. Although this group was relatively smaller in sample size, it was also somewhat lower in mean steps/day in addition to representing a more vulnerable age group.

A higher correlation is anticipated with a briefer time span between assessments [1]. Accordingly, the relatively higher correlations observed herein compared to the more prolonged duration between pedometer-based assessments of the Swedish adolescents [2] is somewhat anticipated. In contrast, however, Jackson et al. [6] reported correlations of 0.40 (Spearman) to 0.49 (Pearson) (again, generally lower than those we found) in 3-4 years old children assessed one year apart with accelerometers. Together, these findings suggest that physical activity behavior tracking may be more stable from year to year in adulthood, at least until older age groups (this last especially for women). Developing children and transitioning adolescents are exposed to continually changing personal, 
Table 2: Sex-and BMI-defined weight category strata of mean \pm SD steps/day

\begin{tabular}{|c|c|c|c|c|c|}
\hline & $\begin{array}{c}\text { TI } \\
\text { Steps/day }\end{array}$ & $\begin{array}{c}\text { T2 } \\
\text { Steps/day }\end{array}$ & $\begin{array}{c}\text { Pearson's } \\
r\end{array}$ & $\begin{array}{c}\text { Spearman's } \\
r\end{array}$ & $\begin{array}{c}\Delta=\text { T2 - T I } \\
\text { Steps/day } \\
(95 \% \mathrm{Cl})\end{array}$ \\
\hline \multicolumn{6}{|c|}{ Normal weight $=\mathrm{BMI}<25 \mathrm{~kg} / \mathrm{m}^{2}$} \\
\hline Males $(n=167)$ & $9,220 \pm 3,808$ & $9,066 \pm 3,571$ & $.691 *$ & $.669 *$ & $\begin{array}{c}-157 \pm 2,907 \\
(-601,287)\end{array}$ \\
\hline Females $(n=373)$ & $8,870 \pm 3,189$ & $8,739 \pm 3,178$ & $.597^{*}$ & $.564^{*}$ & $\begin{array}{l}131 \pm 2,859 \\
(-422,160)\end{array}$ \\
\hline \multicolumn{6}{|c|}{ Overweight $\geq \mathrm{BMI}=25 \mathrm{~kg} / \mathrm{m}^{2}$ to $<30 \mathrm{~kg} / \mathrm{m}^{2}$} \\
\hline Males $(n=243)$ & $8,944 \pm 3,611$ & $8,481 \pm 3,542$ & $.573 *$ & $.511 *$ & $\begin{array}{c}-463 \pm 3,306 \\
(-880,-45)\end{array}$ \\
\hline Females $(n=205)$ & $8,679 \pm 3392$ & $8,704 \pm 3,308$ & $.524^{*}$ & $.539 *$ & $\begin{array}{l}25 \pm 3,270 \\
(-425,475)\end{array}$ \\
\hline \multicolumn{6}{|c|}{ Obese $=\mathrm{BMI}>30 \mathrm{~kg} / \mathrm{m}^{2}$} \\
\hline Males $(n=81)$ & $7,318 \pm 2,957$ & $7,555 \pm 2,961$ & $.525^{*}$ & $.511 *$ & $\begin{array}{c}238 \pm 2,886 \\
(-400,876)\end{array}$ \\
\hline Females $(n=106)$ & $7,564 \pm 2,926$ & $8,193 \pm 3,284$ & $.425^{*}$ & $.467^{*}$ & $\begin{array}{c}629 \pm 3,344 \\
(-15,1274)\end{array}$ \\
\hline
\end{tabular}

*correlation is significant at the 0.01 level (2-tailed)

social, and physical environments, so some degree of instability in behavioral tracking is to be expected. The relative stability of these adults in their behavior, however, is especially interesting, given that the entire sample studied relocated between assessments.

The reasons that people relocate often differ as a function of their place in the lifecycle: younger and middle aged adults relocate for professional and personal opportunities while older adults often relocate for improved access to amenities and to be closer to family [20]. The process of relocation in generally considered a stressful life event [21], especially if it requires long distance moves accompanied with inevitable adjustments to new environments, services, and supports [20]. However, all of the participants in this study were already residents of Perth, Western Australia prior to relocating again within this community to different neighborhoods and locales; disruptions associated with long distance moves should therefore be considered minimal. Regardless the magnitude and scope of this now common life interruption, however, it is remarkable to note the overall stability of behavior (whether active or inactive) between time points in these adults. Overall, $25.9 \%$ of participants were stably inactive and $46.4 \%$ were stably active. From a health perspective, the higher proportion of those who are stably active is desirable, of course [2].

Exploring relative stability/change using a simple stratified analysis and Chi-square testing, we observed signifi- cant differential tracking patterns by sex, age, and BMIdefined weight categories. For example, when steps/day were categorized dichotomously and then evaluated for stability of such categorization over time, an age-related pattern was apparent for females, but not for males. However, it is also interesting to scrutinize the groups that changed their physical activity behavior over just one year. For example, of the ten specific sex-and-age strata studied, eight demonstrated a greater proportion of individuals who decreased their behavior compared to those who increased their behavior. This is an interesting finding worth pursuing in terms of confirmation and further exploration within other data sets; promoting maintenance of higher physical activity levels may be a separate and important approach to population health as opposed to focusing primarily on interventions directed at increasing behavior of sedentary individuals.

Overall, however, a tracking pattern of steps/day (expressed as a continuous variable) appeared to be most influenced by BMI-defined weight status. Further, relative stability of behavior (expressed as a categorical variable) appeared to be moderated by BMI-defined weight status for both sexes. To emphasize, normal weight individuals were more stable in their behavior (i.e., they maintained their position within the group) over time in contrast to those classified as obese. Scrutinizing Figure 2 further reveals that the proportion of obese individuals who increased their physical activity over the previous year was higher than those who decreased their behavior. Whether 
Males
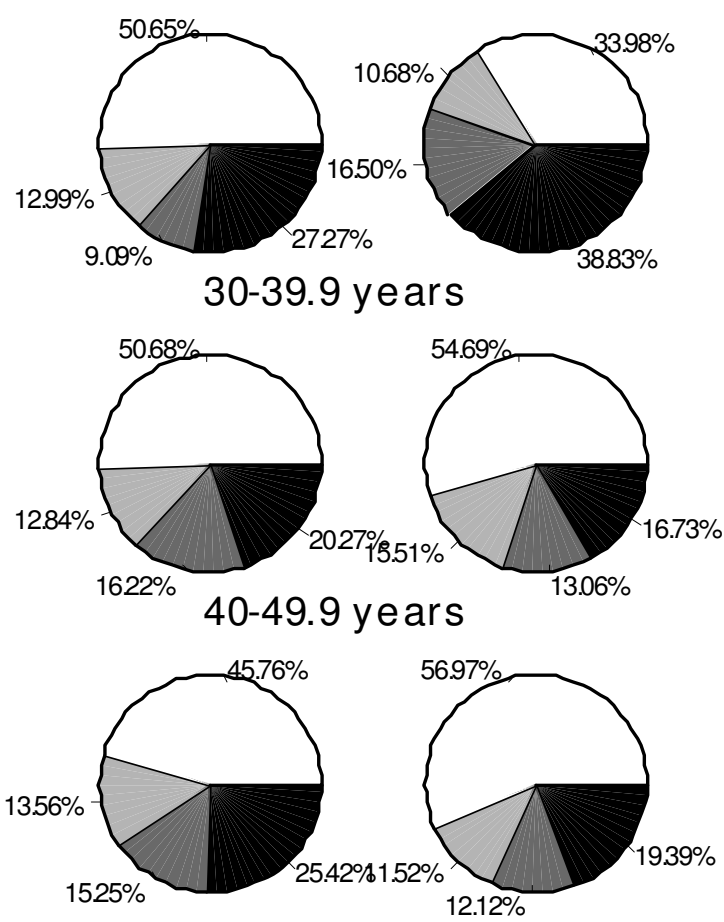

50-59.9 years

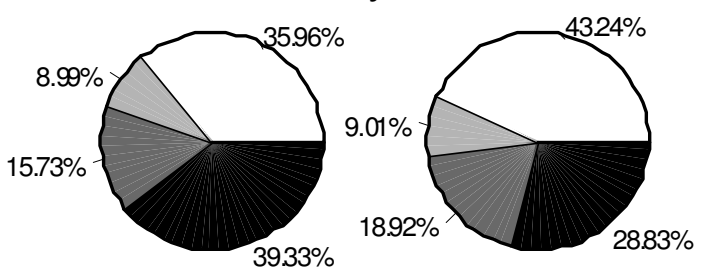

60-oldest
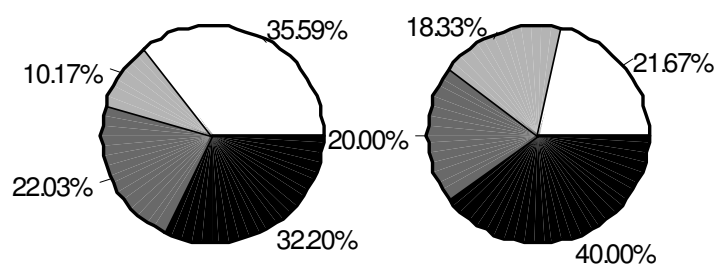

\section{Figure I}

Change/stability in steps/day (cut at 7,500 steps/day) by sex and age category. Stably inactive $<7,500$ steps/day; decreased activity (moved from $\geq 7,500$ to $<7,500$ steps/day between TI and T2); increased activity (moved from $<7,500$ to $\geq$ 7,500 steps/day between TI and T2); and, stably active $\geq 7,500$ steps/day at both time points.

this phenomenon is merely regression to the mean (since those with higher BMI tend to take fewer steps/day) or a result of a wider spread personal decision to change behavior (perhaps driven by a motivation to influence weight) is a question worthy of future research.

A number of study limitations must be noted. Although this study of objectively monitored physical activity repre- sents an improvement over self-report estimates, pedometers are not designed to detect intensity of movement. We are therefore unable to make firm conclusions about individual's participation in health-related quantities of at least moderate intensity physical activity, an outcome of public health interest [22]. However, using the cut point of 7,500 steps/day is a defensible proxy threshold value for a healthful level of physical activity [16-18]. Further, 


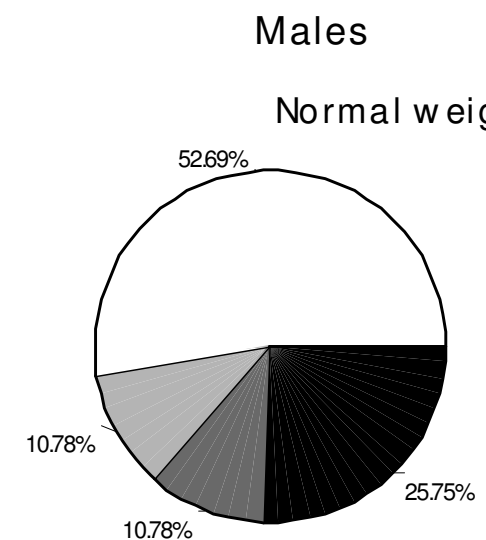

\section{Females}

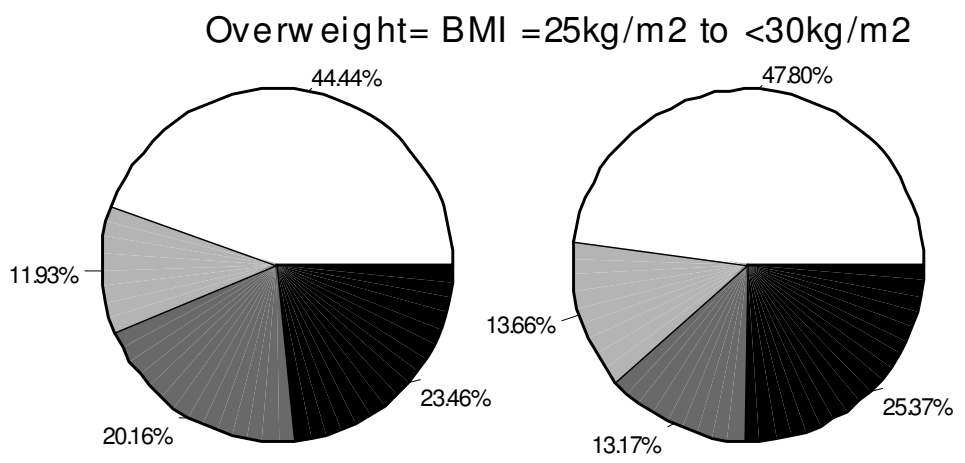

Obe se $=\mathrm{BMl}>30 \mathrm{~kg} / \mathrm{m} 2$
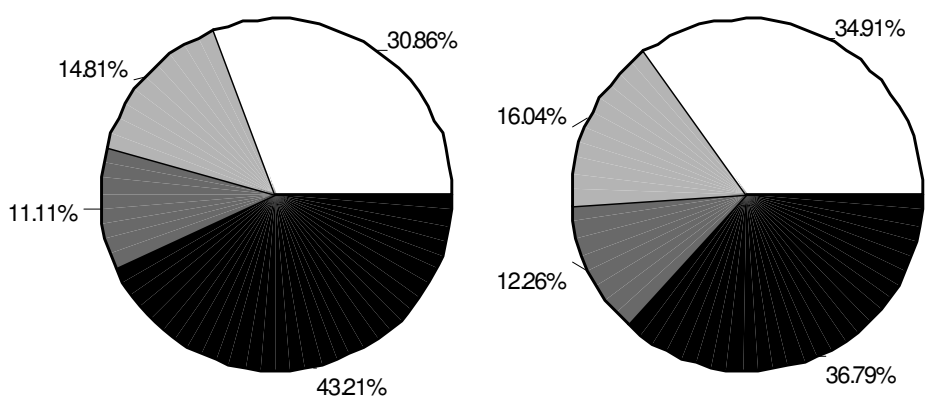

\section{Figure 2}

Change/stability in steps/day (cut at 7,500 steps/day) by sex and BMI-defined weight category. Stably inactive < 7,500 steps/day; decreased activity (moved from $\geq 7,500$ to $<7,500$ steps/day between TI and T2); increased activity (moved from $<7,500$ to $\geq 7,500$ steps/day between TI and T2); and, stably active $\geq 7,500$ steps/day at both time points.

pedometers "miss" or underestimate non-ambulatory activities like weight training and cycling, and because they are not worn during water activities, swimming is not detected at all [23]. However, such activities account for only a small proportion of physical activity on a population level and the estimated average underestimation is approximately 300-700 steps/day [23]. Another limitation of this study is that weight and height were selfreported; estimates of overweight and obesity may therefore be underestimated [24]. Regardless of this potential bias, however, we were still able to observe clear moderating effects of BMI-defined weight categories on tracking of pedometer-determined physical activity. As is often the case for longitudinal studies, attrition is a threat to validity. Although study recidivism is evident, the data herein is reasonably representative of the originally recruited sample. These data, are of course, limited in their generalizability to populations most similar to Perth, Western Australia. Using similar pedometer brands, this sample $\cong$ 8,600 steps/day) was more similarly active compared to a

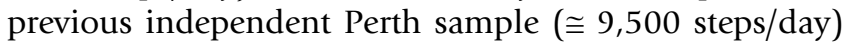

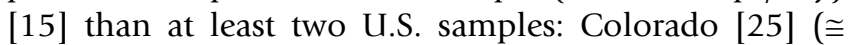
6,800 steps/day) and South Carolina ( $\cong 5,900$ steps/day) [26]. 
In summary, in terms of pedometer-assessed physical activity, Western Australian adults held their rank position within groups to a moderate to moderately high extent (with few exceptions) between assessments separated by one year and disrupted by relocation. The observed pattern of change in steps/day was not influenced by sex or age, but was influenced by BMI-defined weight categories. Categorized and expressed as relative stability/change over time (i.e., stably inactive, decreased activity, increased activity, stably active), sex, age, and BMI patterns were evident. Of concern was the observation that individuals more frequently decreased (than increased) their physical activity over one year. Although not within the scope of this current study, it is possible to examine the additional demographic, personal, and environmental correlates of those categorized according to their relative stability or change between assessments points in future work.

\section{Competing interests}

The authors declare that they have no competing interests.

\section{Authors' contributions}

CTL conceived of the secondary analysis and lead analysis, interpretation and writing. BGC designed the original study, participated in design, interpretation and writing of this secondary analysis. MK contributed to the design of the original study and assisted with analysis, interpretation and writing. GMcC was involved in original data management and contributed to interpretation and writing. All authors read and approved the final manuscript.

\section{Acknowledgements}

Funding from the Western Australian Health Promotion Foundation (Healthway) is gratefully acknowledged (Grant No. I I828). BGC is supported by a NHMRC Senior Research Fellowship (\#503712) and GMcC by an Alberta Heritage Foundation for Medical Research Postdoctoral Research Fellowship.

\section{References}

I. Malina RM: Tracking of physical activity and physical fitness across the lifespan. Res Q Exerc Sport 1996, 67(3 Suppl):S48-57.

2. Raustorp A, Svenson K, Perlinger T: Tracking of pedometerdetermined physical activity: a 5-year follow-up study of adolescents in Sweden. Pediatr Exerc Sci 2007, 19(2):228-238.

3. Janz KF, Dawson JD, Mahoney LT: Tracking physical fitness and physical activity from childhood to adolescence: the muscatine study. Med Sci Sports Exerc 2000, 32(7): I250-1257.

4. Telama R, Yang X, Viikari J, Valimaki I, Wanne O, Raitakari O: Physical activity from childhood to adulthood: a $2 \mathrm{I}$-year tracking study. Am J Prev Med 2005, 28(3):267-273.

5. Caspersen CJ, Pereira MA, Curran KM: Changes in physical activity patterns in the United States, by sex and cross-sectional age. Med Sci Sports Exerc 2000, 32(9):160I-1609.

6. Jackson DM, Reilly JJ, Kelly LA, Montgomery C, Grant S, Paton JY: Objectively measured physical activity in a representative sample of 3- to 4-year-old children. Obes Res 2003, I I(3):420-425.

7. Kelly LA, Reilly J], Jackson DM, Montgomery C, Grant S, Paton JY: Tracking physical activity and sedentary behavior in young children. Pediatr Exerc Sci 2007, 19(1):5I-60.
8. Parsons TJ, Power C, Manor O: Longitudinal physical activity and diet patterns in the 1958 British Birth Cohort. Med Sci Sports Exerc 2006, 38(3):547-554.

9. U.S. Census Bureau, Population Division, Journey-To-Work \& Migration Statistics Branch: Geographic Mobility: 2004 to 2005. [http://www.census.gov/population/www/socdemo/migrate/ cps2005.html].

10. Australian Bureau of Statistics: Australians on the move. [http:// www.abs.gov.au/Ausstats/abs@.nsfl 947|3ad445ffl 425ca25682000|92af2/ 8I2343b3e6694d5dca256d3c000If4c9!OpenDocument].

II. Giles-Corti B, Knuiman M, Timperio A, Van Niel K, Pikora T], Bull FC, Shilton T, Bulsara M: Evaluation of the implementation of a state government community design policy aimed at increasing local walking: Design issues and baseline results from RESIDE, Perth Western Australia. Prev Med 2008, 46(I):46-54.

12. Crouter SE, Schneider PL, Karabulut M, Bassett DR Jr.: Validity of 10 electronic pedometers for measuring steps, distance, and energy cost. Med Sci Sports Exerc 2003, 35(8): | 455- I 460.

13. Schneider PL, Crouter SE, Lukajic O, Bassett DR Jr.: Accuracy and reliability of 10 pedometers for measuring steps over a 400 m walk. Med Sci Sports Exerc 2003, 35(10): 1779-1784.

14. Rowe DA, Mahar MI, Raedeke TD, Lore J: Measuring physical activity in children with pedometers: Reliability, reactivity, and replacement of missing data. Pediatr Exerc Sci 2004, 16(4):343-354.

15. McCormack G, Giles-Corti B, Milligan R: Demographic and individual correlates of achieving 10,000 steps/day: use of pedometers in a population-based study. Health Promot J Austr 2006, I7(I):43-47.

16. Jordan AN, Jurca GM, Locke CT, Church TS, Blair SN: Pedometer indices for weekly physical activity recommendations in postmenopausal women. Med Sci Sports Exerc 2005, 37(9): 1627-1632.

17. Sugiura $H$, Sugiura $H$, Kajima K, Mirbod SM, Iwata $H$, Matsuoka $T$ : Effects of long-term moderate exercise and increase in number of daily steps on serum lipids in women: randomised controlled trial . BMC Womens Health 2002, 2(1):3.

18. Tudor-Locke C, Bassett DR Jr.: How many steps/day are enough? Preliminary pedometer indices for public health. Sports Med 2004, 34(I): I-8.

19. Fortier MD, Katzmarzyk PT, Malina RM, Bouchard C: Seven-year stability of physical activity and musculoskeletal fitness in the Canadian population. Med Sci Sports Exerc 200I, 33(II): 1905-1911.

20. Koenig CS, Cunningham WR: Adulthood relocation: implications for personality, future orientation, and social partner choices. Exp Aging Res 200I, 27(2):197-213.

21. Lutgendorf SK, Reimer TT, Schlechte J, Rubenstein LM: IIIness episodes and cortisol in healthy older adults during a life transition. Ann Behav Med 200I, 23(3): I66-I76.

22. Haskell WL, Lee IM, Pate RR, Powell KE, Blair SN, Franklin BA, Macera CA, Heath GW, Thompson PD, Bauman A: Physical activity and public health: updated recommendation for adults from the American College of Sports Medicine and the American Heart Association. Med Sci Sports Exerc 2007, 39(8): I 423-1 434.

23. Miller R, Brown W, Tudor-Locke C: But what about swimming and cycling? How to "count" non-ambulatory activity when using pedometers to assess physical activity. Journal of Physical Activity and Health 2006, 3:257-266.

24. Flood V, Webb K, Lazarus R, Pang G: Use of self-report to monitor overweight and obesity in populations: some issues for consideration. Aust N Z J Public Health 2000, 24(I):96-99.

25. Wyatt HR, Peters JC, Reed GW, Barry M, Hill JO: A Colorado statewide survey of walking and its relation to excessive weight. Med Sci Sports Exerc 2005, 37(5):724-730.

26. Tudor-Locke C, Ham SA, Macera CA, Ainsworth BE, Kirtland KA, Reis JP, Kimsey CD Jr.: Descriptive epidemiology of pedometer-determined physical activity. Med Sci Sports Exerc 2004, 36(9): 1567-1573. 